\title{
DETERMINANTS OF DISEASE AND DISABILITY IN THE ELDERLY: THE ROTTERDAM ELDERLY STUDY
}

\author{
A. HOFMAN ${ }^{1}$, D.E. GROBBEE, P.T.V.M. DE JONG \\ and F.A. VAN DEN OUWELAND \\ Department of Epidemiology \& Biostatistics and Department of Ophthalmology, \\ Erasmus University Medical School, PO Box 1738, 3000 DR \\ Rotterdam, The Netherlands.
}

Key words: Aging - Cohort study - Determinants - Disease - Epidemiology - Followup study

\begin{abstract}
In this paper the Rotterdam Elderly Study is presented. The aim of the study is to investigate determinants of disease occurrence and progression in the elderly. In addition to contributing to our understanding of the etiology of geriatric illnesses, the study is expected to lead to specific recommendations for intervention. The study focusses on causally related determinants of major diseases in the elderly. Fields of interest for the Rotterdam Elderly Study are conditions which interfere the most with the quality of life for the elderly. The aims of the Rotterdam Elderly Study are:

(1) To investigate, by means of epidemiologic, clinical and basic research, the determinants of diseases in order to assess their etiologic significance.

(2) To investigate potentially modifiable determinants in order to be able to develop preventive strategies by providing specific recommendations for intervention studies.

The Rotterdam Elderly Study focusses on four primary areas of research: neurogeriatric diseases, cardiovascular diseases, locomotor diseases and ophthalmologic diseases. It is a prospective follow-up study, in which determinants of disease and determintants of progression of disease will be investigated in the total population of 55 years or over of the district of Ommoord in Rotterdam. It is anticipated that about 10,000 people will participate in the study and they will be examined in the period of 1991 to 1995.
\end{abstract}

\section{GENERAL DESCRIPTION OF THE ROTTERDAM ELDERLY STUDY}

\subsection{Introduction}

Due to increased longevity in the last decades, the elderly form a substantial and growing part of the population. Age-related illnesses with chronic

\footnotetext{
1 Corresponding author.
}

characteristics, e.g. Alzheimer's disease, visual impairment, cardiovascular and locomotor diseases, affect large numbers of people and have a dramatic impact on the quality of life. It is obvious that a delay in the onset of chronic diseases will reduce the time spent with some form of disability and may limit the otherwise expected reduction in quality of life. However, before interventive action can be advocated with confidence more must be known about the etiology of geriatric diseases, especially with respect to potentially modifiable risk factors. The Rotterdam 
Elderly Study focusses on the study of etiology by investigating the incidence and determinants of occurrence of important chronic diseases. The investigation of potentially modifiable risk factors is one of the major objectives of the Rotterdam Elderly Study. This knowledge may lead to the testing of specific preventive and therapeutic measures by randomized controlled trials in defined high-risk groups. The primary target is improvement in quality of life by reducing morbidity in the elderly.

\subsection{The Rotterdam Elderly Study, scope of research}

The Rotterdam Elderly Study is a longitudinal population study designed to investigate determinants of the incidence and progression of diseases in the elderly. The aims of the study are two-fold:

(1) To investigate, by means of epidemiologic, clinical and basic research, determinants of chronic diseases in order to assess etiologic significance.

(2) To investigate potentially modifiable determinants in order to be able to provide specific recommendations that, once confirmed by intervention studies, may be developed into preventive strategies. The study focusses on four primary areas of research: neurogeriatric diseases, cardiovascular diseases, locomotor diseases and ophthalmologic diseases. The primary and secondary research questions in each of these areas are described in chapter 2.

\subsection{Rationale}

The number of elderly patients with chronic illnesses is rising rapidly. The mean duration of life is longer than ever, but the quality of life in the years of old age seems to be declining (96). Life expectancy at birth has been increasing since the beginning of this century, for the most part due to diminished perinatal and infant mortality (Figure 1): Although less
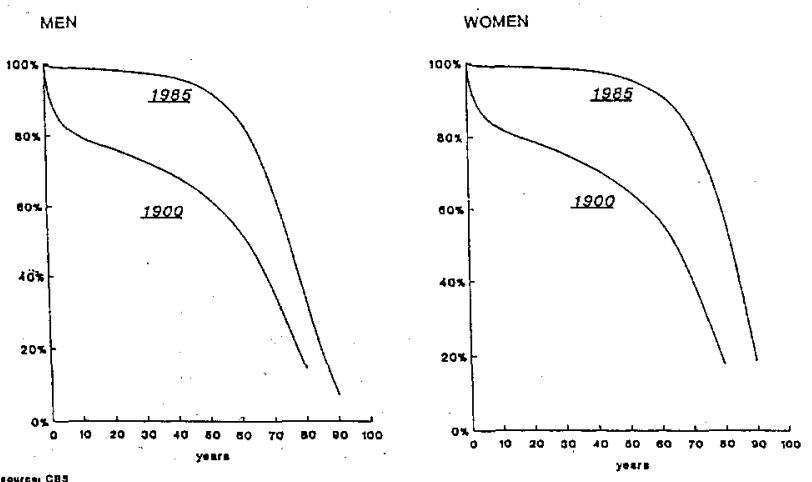

Figure 1.

Survival curves for men and women, 1900 and 1985, The Netherlands. spectacularly, life expectancy at middle and old age has also increased somewhat (Figure 2). Assuming that the life span of the human species is finite and close to that of today, a continuation of the squaring of the survival
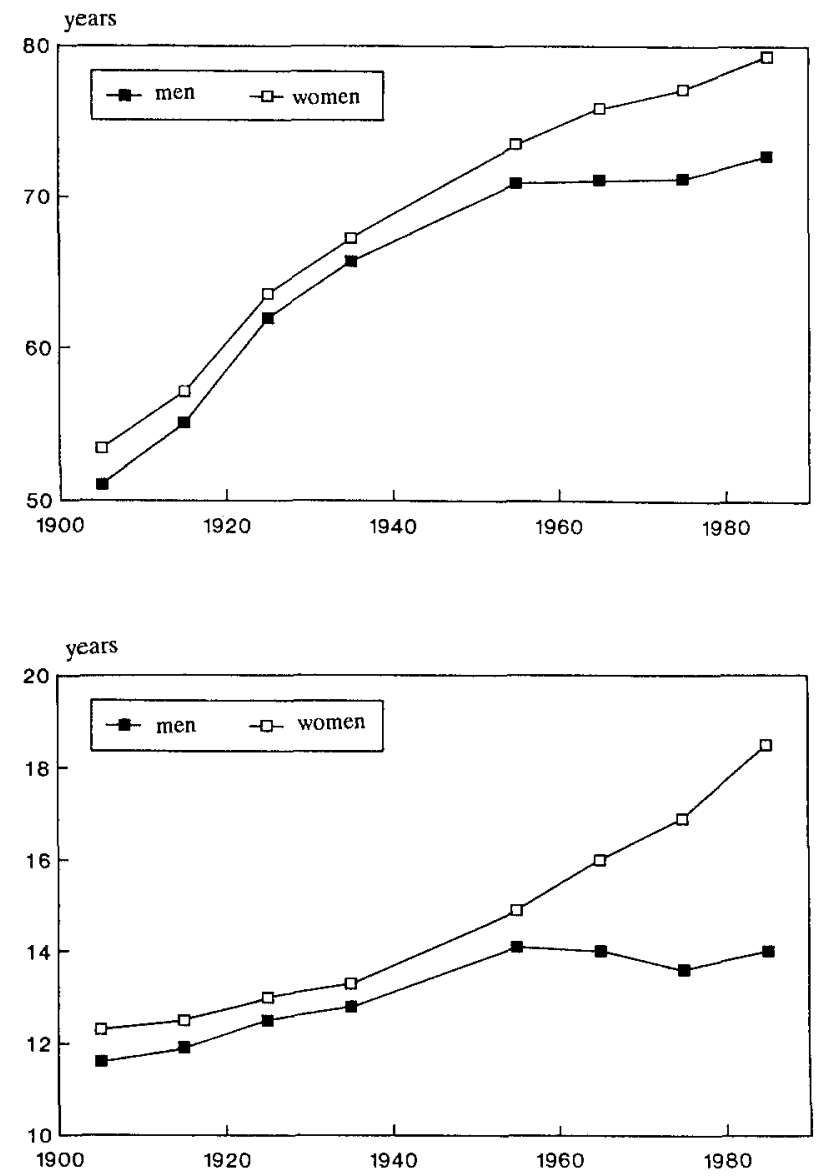

Figure 2.

Life expectancy at birth (upper part) and at age 65 years (lower part) of men and women, The Netherlands.

curve with time (Figure 1) is to be expected. This process is described as the compression of mortality (28). Today, however, when there is a fair chance of reaching the 7th decade, it is not a further increase in life expectancy at that age but improvement in health and well-being which deserves priority. A major contribution to quality of life of the elderly may be achieved when postponement of the onset of chronic illnesses is realized. Therefore, there is a clear need for preventive measures aimed at the compression of morbidity in the elderly $(29,34,61)$.

Prevention, however, requires specific knowledge of determinants of the disease at issue. The discipline of epidemiology is concerned with the study of disease occurrence, especially the association of disease 
occurrence or prognosis with putative determinants. Putative risk factors of disease or disease progression are best studied in collaboration with other disciplines of medical science to determine their clinical and etiologic relevance.

The research projects of the Rotterdam Elderly Study focus on those age-related conditions that significantly contribute to chronic illness and disability in the aged population: dementia, cardiovascular diseases, osteoporosis and osteoarthritis, and visual impairment. Some selected data on the frequency of occurrence of these diseases is shown in Figures 3, 4 and 5.

The investigation of potentially modifiable risk factors, one of the aims of this study, is motivated by the fact that it may be possible to develop preventive strategies. Prevention of illness and disability is the natural first step toward eliminating disease-induced impairment of the quality of life. There are no a priori grounds for assuming that preventive strategies for the

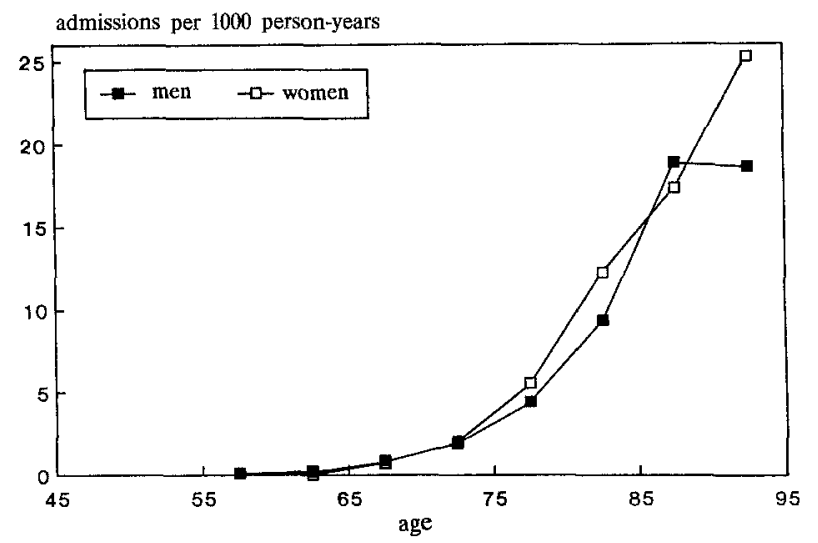

Figure 3.

Average incidence rate (per 1000 personyears) of hospitalisation for dementia, in Rotterdam, The Netherlands, $1981-1985$.

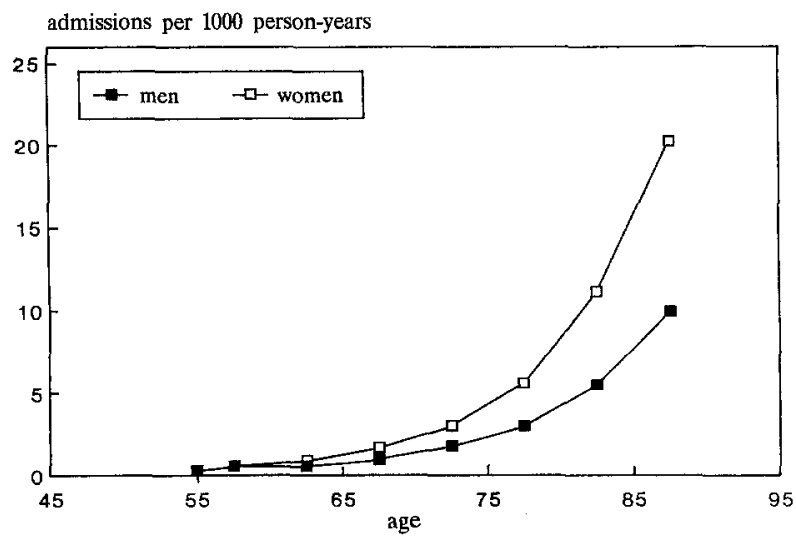

Figure 4.

Average incidence rate (per 1000 personyears) of hospitalisation for hip fracture in The Netherlands, 1967 - 1979.

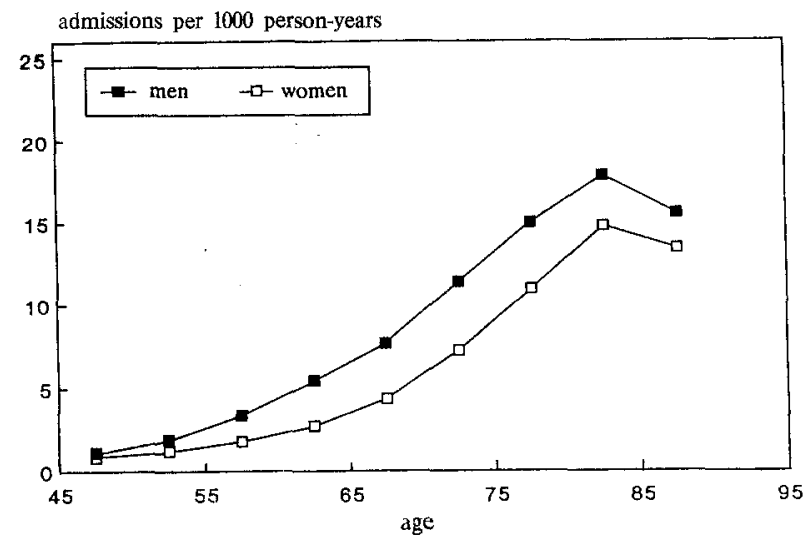

Figure 5.

Average incidence rate (per 1000 personyears) of hospitalisation for cerebro-vascular accident in The Netherlands, 1986.

aged would not be worthwhile (29). The medical examination of healthy subjects who do not directly benefit from this procedure is justified by the fact that epidemiologic research of the past twenty years has contributed significantly to current knowledge of chronic disease etiology.

\subsection{Design of the Rotterdam Elderly Study}

\subsubsection{Overview}

The Rotterdam Elderly Study is a prospective follow-up study. All participants are extensively examined at the time of enrollment. After 2.5 years every participant will be re-examined using identical procedures. Incident morbidity, changes in disease determinants and, eventually, cause-specific death will be recorded. Comparison with baseline data will provide estimates of incidence. Moreover, it will be possible to investigate the occurrence of disease with respect to specific determinants efficiently by the casecontrol approach within the cohort.

\subsubsection{Study cohort}

The study cohort was defined as all inhabitants aged 55 years and older of one district of Rotterdam (Ommoord), who live there at a specific point in time and are willing to participate in the study. Potential participants will be invited in random clusters. Names and addresses will be drawn from the municipal register which is reliable, complete and up to date. The number of eligible subjects is 11,850 (see Table 1). The response rate, according to the results of a pilot study, is expected to be over 80 per cent. 
TABLE 1. - Demographic data for the district of Ommoord in Rotterdam.

\begin{tabular}{lrrr}
\hline age & number of men & number of women & total \\
\hline $55-59$ & 904 & 1,040 & 1,944 \\
$60-64$ & 917 & 1,032 & 1,949 \\
$65-69$ & 841 & 1,090 & 1,931 \\
$70-74$ & 685 & 1,014 & 1,699 \\
$75-79$ & 549 & 964 & 1,513 \\
$80-84$ & 344 & 1,007 & 1,351 \\
$85-89$ & 239 & 762 & 1,001 \\
$90+$ & 94 & 372 & 466 \\
Total & 4,573 & 7,281 & 11,854 \\
\hline
\end{tabular}

\subsubsection{Protocol}

To obtain baseline data an initial home visit and interview by a trained research assistant will be followed by a physical examination. Health status, putative risk factors, and anthropometric and clinical variables will be assessed in a standardized manner by trained paramedical assistants and physicians. The medical examination will be performed at the field center of the Rotterdam Elderly Study, located in the heart of the district of Ommoord. At follow-up, about 2.5 years after enrollment, changes in health status and clinical measurements will be assessed by reexamination at the center. Incident cases of disease, as well as cause-specific deaths will be monitored during the study period by observing the diagnostic procedures of the formal health care system. Thus, essential data on morbidity endpoints and vital status will be available for conclusions based on person-time-related observations.

\subsubsection{Informed consent}

The Rotterdam Elderly Study has been approved by the Medical Ethics Committee. Each eligible person will receive written and oral information about the goals and research methodology of the study, together with a description of the examinations involved. Respondents will be asked to sign a consent form.

\subsection{Measurements}

A short list of the baseline measurements is given here. For a detailed description of the measurements the reader is referred to the Manual of Operations of the Rotterdam Elderly Study, which is available upon request.

* Medical data: medical history, dietary history, present medical complaints, pharmacotherapy, use of medical services.
* Socio-economic data: social and economic status, housing and living conditions.

* Geriatric status: mental status questionnaires, mobility.

* Physical examination: anthropometry, sphygmomanometry, neurologic examination.

* Ophthalmologic examination: visual acuity, tonometry, fundus photography, perimetry.

* Additional measurements: electrocardiography, ultra-sonographic examinations of carotid and aortic vessel walls, radiography, dual X-ray absorptiometry.

* Laboratory examination: samples of blood and urine are collected for hemostatic determinations, routine clinical chemistry and specific additional tests.

\subsection{Time schedule}

The Rotterdam Elderly Study entered its pilot phase in 1989. Full participant recruitment and complete data acquisition started in 1990. Follow-up examinations will start in January 1993. The whole study in expected to run until 1995.

\section{RESEARCH PROJECTS}

The Rotterdam Elderly Study has research projects in four areas: neurogeriatric diseases, cardiovascular diseases, locomotor diseases and ophthalmologic diseases. The aims and design of these projects will be described in some detail here.

\subsection{Neurogeriatric diseases}

\subsubsection{Introduction}

The neurogeriatric diseases, including dementia and Parkinson's disease, are major public health problems. The frequency of dementia is, even according to conservative estimates, very high $(37,86)$. Recent evidence suggests that the prevalence of severe dementia in the Netherlands is at least $5 \%$ of those aged 65 years or over, and $25 \%$ of those aged 85 years or over (43). The prevalence of both dementia and Parkinson's disease rises sharply with age. The burden of these diseases, for patients and their families as well as the community, is very high. The economic costs of dementia and Parkinson's disease, in particular for nursing home care, are enormous and will continue to increase with the rising prevalence of the diseases. It is estimated that by the year 2000 , psychogeriatric nursing home costs will grow from $33 \%$ to $42 \%$ of the Dutch national mental health care budget (6). These considerations have led to the present study of the incidence and risk factors of the dementing illnesses and the prevalence of Parkinson's disease. 


\subsubsection{Research questions}

1. What is the incidence of dementia, specifically Alzheimer's disease, vascular dementia, mixed dementia and other dementia's?

2. What are the risk factors for the various types of dementia?

3. What is the prevalence of Parkinson's disease among the elderly?

\subsubsection{Rationale}

Dementia is one of the most important causes of severe disability in the elderly. Research into the frequency of the dementing illnesses has been limited so far to studies of the prevalence and incidence of hospitalization for dementia $(43,86)$. However, a sizable proportion of the patients suffering from dementia are not admitted to hospitals or nursing homes. This applies in particular for dementia occurring at a late age, e.g. after the age of 70 . The lack of information about the true incidence of dementia is an important motive for the present study. From an etiologic viewpoint it is important to distinguish between the various forms of dementia that have a different pathophysiological background $(16,35,39$, $62,108)$. For studies on the incidence of the dementing illnesses this implies that diagnostic facilities have to be available in order to be able to diagnose the subtypes of dementia, and that the size of the study cohort has to be sufficient to obtain stable estimates of the incidence for each subtype. The major subtypes considered in this study are: Alzheimer's disease, vascular dementia, mixed dementia and other dementia's.

The primary aim of this study is to identify preventable causes of the dementing illnesses, by investigating risk factors for dementia. This study will provide data that may lead to further intervention research aimed at preventing dementia. The following putative risk factors are considered important in view of the possibilities for prevention:

(1) Vascular factors: $(35,91)$ vascular (multiinfarct) dementia is likely to be strongly associated with both atherosclerosis and risk factors for cardiovascular disease (see also chapter 2.2). Intervention in factors that cause atherosclerotic vascular lesions appears to be a likely means of reducing loss of cognitive function.

(2) Traumatic factors: $(3,12,41,69,98)$ head trauma is in principle a preventable cause of dementia. This is particularly the case because head trauma may be an important cause of dementia in terms of attributable risk.

(3) Toxicologic and nutritional factors:(94) aluminum intake has been implicated in the etiology of Alzheimer's disease; other micronutrients, particularly selenium, have also been suggested as risk factors for dementia.

It is essential to study the role of genetic factors in the etiology of Alzheimer's disease, because of the interactions between genetic factors and other risk factors (42). As far as prevention is concerned this implies that it is necessary to identify those individuals who are susceptible to environmental risk factors. This underlines the importance of in-depth studies of genetic factors in those known to have other putative risk factors for the dementing illnesses. Therefore, the need for joint epidemiologic, molecular biological and immunologic studies is emphasized (see subprojects in 2.1.5).

\subsubsection{Study design}

\subsubsection{General design}

The study is designed as a prospective follow-up study. In the initial phase of the study (baseline examination) patients already suffering from dementia will be detected. In this initial phase putative risk factors for dementia will be measured. Subjects who are free of dementia at the first examination will be reexamined after an average of 2.5 years. This follow-up study will yield new cases of dementia, which will enable us to estimate the incidence rate of dementia and its subtypes. It is estimated that at least 180 new patients with dementia will occur in about 22,000 person-years (about 10,000 subjects followed for an average of 2.5 years, after subtraction of deaths). This is considered to be sufficient to obtain a stable estimate of the incidences of Alzheimer's disease, vascular dementia, mixed dementia and other dementia's. These 180 incident cases will also suffice to investigate potential risk factors for dementia and its subtypes.

\section{Methodology}

The incidence study will be performed as part of an investigation of variations in the incidence of dementia in countries of the European Community. An adaptation of the Geriatric Mental State (GMS) in combination with the Mini Mental State Examination (MMSE) will be used as screening instrument in the initial phase of the study $(18,22,49)$. The GMS yields a preliminary diagnosis of dementia at 6 levels of diagnostic reliability. It is expected that approximately $20 \%$ of the initial group will be positive according to the GMS. This group will undergo a second examination to confirm the diagnosis of dementia. Upon confirmation a specific neurologic and geriatric examination will be conducted, including laboratory tests and Magnetic Resonance Imaging (MRI).

\section{Putative risk factors}

The aim of the study is to detect preventable causes of dementia. During the initial phase (baseline examination) a variety of possible determinants of the 
incidence of dementia will be measured. The putative risk factors are separated into the following major categories: genetic factors, vascular factors, immunologic factors, virologic factors, toxicologic factors, nutritional factors and traumatic factors.

* Genetic factors: family history of dementia, Down's syndrome, leukemia, Parkinson's disease, epilepsy;

* Vascular factors: atherosclerotic vessel lesions, blood pressure, lipids, smoking habits; hemostatic variables;

* Immunologic factors: family history of (auto) immune diseases; serology of bacterial infections; auto-immune antibodies;

* Virologic factors: history of virus infection; titers of neurotropic viruses;

* Toxicologic factors: occupational risk, medication, aluminum;

* Nutritional factors: micronutrient intake; alcohol intake;

* Traumatic factors: head trauma, anesthesia.

\subsubsection{Specific projects}

\section{(1) Genetic factors: molecular linkage analysis}

In several families Alzheimer's disease segregates as an autosomal dominant disorder. In these families, molecular genetic studies have suggested linkage to polymorphic DNA markers on the proximal long arm of chromosome 21. In the Rotterdam Elderly Study, full pedigree information on the history of dementia in first degree relatives will be obtained from all subjects. Families with more than one dementia patient will enter an ongoing genetic study of familial Alzheimer's disease. In this study molecular linkage analysis with recently developed polymorphic markers, in order to localize the putative Alzheimer's gene on chromosome 21 , will be carried out. The presence of polymorphic markers on chromosome 21 will be compared between patients with early and late onset familial Alzheimer's disease.

\section{(2) Genetic factors: DNA repair}

Several studies have reported decreased DNA repair in patients with Alzheimer's disease. It has been hypothesized that this defect leads to an accumulation of lesions in the central nervous system and may thus play a role in the pathogenesis of Alzheimer's disease. In this project, DNA repair in all incident Alzheimer patients and age- and sex-matched controls drawn randomly from the study population will be compared. There is evidence that a decrease in DNA repair is specific for the subpopulation of familial Alzheimer patients, whose disease is most likely of genetic origin. Therefore, comparisons will be made between familial patients (those with one or more relatives with dementia) and sporadic patients. To determine whether the defect in DNA repair precedes the first symptoms of disease, the offspring of patients from families in which Alzheimer's disease is apparently inherited as an automosal dominant disorder will also be examined.

\section{(3) Immunologic factors}

The aim of the immunologic project in the Rotterdam Elderly Study is to investigate impaired T cell reactivity in patients with Alzheimer's disease. For this purpose, responses of $\mathrm{T}$ cells in all incident Alzheimer patients and age- and sex-matched controls drawn randomly from the cohort will be compared. First, the capacity of $T$ cells to divide, produce hormone or lymphokines and express receptors following stimulation will be studied. Secondly, the possibility of improving the reactivity of $\mathrm{T}$ cells from Alzheimer patients with the help of lymphokines and neuroendocrine hormones will be investigated. Patients with Alzheimer's disease will be followed to assess the relationship between $\mathrm{T}$ cell reactivity and severity of the disease. Moreover, familial patients (those with one or more relatives with dementia) and sporadic patients will be compared to see whether the diminished $\mathrm{T}$ cell reactivity is of genetic origin.

\section{(4) Vascular factors}

In this project the roles of blood pressure and other risk factors as determinants of vascular dementia will be investigated. The aim is to develop a risk function which can be used to reach decisions concerning the treatment of mild or moderate hypertension in order to prevent vascular dementia. The risk function will be composed of variables measured during the Rotterdam Elderly Study, including blood pressure (isolated systolic hypertension), history of cerebrovascular disease (with emphasis on TIA's) and other cardiovascular diseases, major cardiovascular risk factors (serum lipids, smoking habits) and ECG characteristics. The risk function will be based on a comparison of these variables among patients with vascular dementia and control subjects. This study may be seen as preparation for an intervention study of the treatment of hypertension to prevent vascular dementia.

\section{(5) White matter brain lesions}

An association between cognitive impairment, white matter lesions in the brain, and cardiovascular disease has long been suspected for a subgroup of patients suffering from dementia. Recent studies with MRI have indicated that the cerebral consequences of a high cardiovascular risk may be even more important and widespread. In this study, the prevalence of white matter lesions will be assessed in a random sample drawn from the study cohort as well as a group of participants at high risk for cardiovascular disease and patients with cognitive impairment. This will allow the identification and quantification of cognitive 
dysfunction due to atherosclerotic vessel disease, and the contribution of "classical" and hemostatic risk factors can be assessed.

\subsection{Cardiovascular diseases}

\subsubsection{Introduction}

The objective of the study of cardiovascular diseases in the Rotterdam Elderly Study is to clarify the determinants of cardiovascular disease in an ageing population. In this study, special emphasis will be placed on the contribution of thrombogenesis and blood vessel wall changes. In the following paragraphs we will briefly discuss the research questions, background and rationale, and design of the study. In addition, a description of the hemostatic parameters measured during the study will be given.

\subsubsection{Research questions}

\section{Primary}

1. What are the determinants of the occurrence and progression of atherosclerotic vessel disease and the development of cardiovascular disease, and what is the role of disturbances in hemostatic function?

2. Is progression of vascular atherosclerotic lesions in asymptomatic elderly patients a prelude to cardiovascular events?

\section{Secondary}

1. What are the prevalence, incidence and determinants of aneurysms of the abdominal aorta?

2. Are risk factors for cardiovascular disease, in particular high blood pressure, associated with cognitive impairment in the elderly and the occurrence of lesions of white brain matter?

3. What is the importance of raised insulin levels in the development of cardiovascular and cerebrovascular disease, and what are its determinants?

4. What are the determinants of deep venous thrombosis in the elderly, and what is the role of genetic or acquired changes in hemostatic function?

5. Is it possible to develop a risk function for vascular dementia that could be used to design subsequent intervention studies?

6. What is the association between social and economic status, social support and the development of cardiovascular disease in the elderly?

\subsubsection{Background and rationale}

\section{Introduction}

In the next decades, an increasing number of elderly people will become severely handicapped or die as a consequence of cardiovascular and cerebrovascular disease $(79,97)$. In addition to the well-known consequences of atherosclerotic vessel disease; myocardial infarction and stroke, the impact of other consequences of atherosclerotic circulatory disturbances (such as peripheral artery disease, aortic aneurysms, congestive heart failure, and vascular dementia) on the quality of life for the elderly is becoming increasingly apparent $(27,33)$.

\section{Primary research questions}

In the search to find factors which would favorably influence the morbidity and mortality due to cardiovascular disease in the elderly, factors which lead to atherosclerosis are exceedingly important. It is the rule rather than the exception that blood vessels in the population over 50 years of age are to a greater or lesser extent affected by atherosclerosis. There is growing agreement that an answer is needed to the question of which factors in the presence of atherosclerosis will lead to symptoms of cardiovascular disease. In this respect, a distinction can be made between factors promoting the vulnerability of the myocardium or the brain to ischemic attacks and factors that trigger significant occlusion of vessels already affected by atherosclerotic changes $(33,74)$. Findings from a number of studies point to hemostatic factors as candidates for the latter category $(21,88)$ There are indications that platelet aggregation and increased activity of a number of clotting factors, reduced effectiveness of clotting inhibiting plasma proteins, and the fibrinolytic system contribute to atherosclerotic and thrombo-embolic complications $(25,52,64,65,104$, $105,107)$. As an example, in a comparison of Japanese men living in different countries with different cardiovascular disease rates, different mean levels of coagulation factors appeared to explain part of the differences in cardiovascular disease, independent of other cardiovascular risk indicators (48). These findings are supported by reports about the efficacy of oral anticoagulants, prostaglandin inhibitors and platelet aggregation inhibitors in the secondary prevention of coronary heart disease and cerebrovascular accidents and in patients with unstable angina pectoris $(4,11,59,76,92)$. In addition, recent findings on the efficacy and risks of aspirin in the prevention of first myocardial infarction demonstrate the importance of the ability to predict who will and who will not profit from such preventive measures (77, 97 ). Disturbances in hemostatic activity which are risk factors for thrombosis increase with ageing (63). Understanding of the part played by hemostatic disturbances in the initiation and progression of vascular lesions and overt cardiovascular disease is one of the main objectives of the cardiovascular project of the Rotterdam Elderly Study. The investigation of the influence of hemostatic factors on atherosclerosis and its morbid sequelae cannot be separated from studies of 
other determinants of cardiovascular disease. Moreover, in view of the fact that atherosclerotic changes most probably promote coagulation, it is necessary to investigate the association between these factors in a prospective study (40).

The most important change in the blood vessel wall at the initiation of cardiovascular diseases is thought to be the formation of atherosclerotic plaques $(75,88)$. An increasing stiffness of the blood vessel wall with age and with certain risk factors has been reported, even in otherwise asymptomatic people (51). More recently, emphasis has been put on arterial wall thickness as a marker of generalized atherosclerosis and cardiovascular risk. The sequence of the development of generalized vessel wall changes and localized atherosclerotic blood vessel lesions as well as the interaction with hemostatic and other cardiovascular risk factors is as yet unknown. The development of reliable non-invasive methods for the imaging of blood vessels enables us to study a large number of asymptomatic subjects $(9,26,68,90)$. The proposed study offers the possibility to clarify the interaction of hemostasis, blood vessel wall changes and cardiovascular disease in ageing people. In the Rotterdam Elderly Study state-of-the-art imaging of the carotid arteries is accompanied by extensive assessment of atherosclerotic involvement in other parts of the cardiovascular system.

Hypertrophy and dilatation of the myocardium are known consequences of long- standing hypertension and chronic myocardial ischemia. Yet, recent findings suggest that changes in the dimensions of the left ventricle may be not only a consequence of hypertension and coronary artery disease but also a potent independent marker of subsequent risk for myocardial infarction and other cardiovascular events (57, 58). As part of the Rotterdam Elderly Study cardiovascular project, the dimensions of the myocardium will be measured by means of echocardiography. In addition, the more conventional approach of assessment of left ventricular hypertrophy by electrocardiography will be applied. Together with imaging of the carotid artery, this will enable us to study the relative contributions of risk factors for cardiovascular disease to myocardial and carotid damage and their respective risks for future morbidity.

The disease parameters and putative determinants selected for the cardiovascular project of the Rotterdam Elderly Study reflect the general objective of the study: to clarify the potential for preventive measures against cardiovascular risk in the elderly.

\subsubsection{Specific projects}

\section{(1) Aneurysms of the abdominal aorta}

Aneurysms of the abdominal aorta will be studied as part of the general assessment of the prevalence, incidence and determinants of vessel wall changes in the elderly and their association with symptomatic cardiovascular disease (70). In addition, the value of various diagnostic strategies in the detection and management of aortic aneurysms will be evaluated from a decision analytic perspective $(78,103)$.

\section{(2) White matter brain lesions}

An association between cognitive impairment, white matter lesions in the brain, and cardiovascular disease has long been suspected for a subgroup of patients suffering from dementia $(7,23,47)$. Recent studies with nuclear magnetic resonance imaging have indicated that the cerebral consequences of the cardiovascular risk status may be much more important and widespread than previously thought (54). In the proposed study, the prevalence of white matter lesions will be assessed in a random sample drawn from the Rotterdam Elderly Study cohort as well as a group of participants at high risk for cardiovascular disease and patients with cognitive impairment. This will lead to the quantification of cognitive dysfunction as a consequence of atherosclerotic vessel disease and the contribution of "classical" and hemostatic risk factors to the disorder.

\section{(3) Diabetes mellitus}

Diabetes is one of the most important risk factors for cardiovascular disease (73). The incidence and prevalence of diabetes are rising in Westernized societies (53), and its burden in terms of economic consequences amounts to more than one third of the total costs of the health effects of cigarette smoking (46). The progression of atherosclerosis in diabetic patients is only partly preventable by controlling glucose metabolism (85). It has been suggested that glucose intolerance and other cardiovascular risk factors (e.g. hypertension, hyperlipidemia), and perhaps the development of atherosclerosis itself, may be different reflections of the same metabolic or enzymatic disturbance leading to insulin resistance and raised insulin levels $(81,95)$. In the proposed study the prevalence of diagnosed diabetes mellitus and nonclinical glucose intolerance, as well as raised plasma insulin levels, will be assessed and their association with vascular disease and the "classical" and hemostatic risk factors explored. In addition, the incidence of raised insulin levels, glucose intolerance, and the determinants of progression of atherosclerotic vessel disease in diabetes will be evaluated during the follow-up period.

\section{(4) Deep venous thrombosis}

The incidence of deep venous thrombosis rises with age, in particular after age 50 , and is associated with substantial morbidity and mortality in the elderly $(10,17)$. In the Rotterdam Elderly Study, all symptomatic cases of deep venous thrombosis and 
pulmonary embolism occurring during the follow-up period will be monitored. These patients will be compared with a reference group randomly drawn from the same population. The comparison will include hemostatic factors (e.g. protein $\mathrm{S}$, protein $\mathrm{C}$ and antithrombin III) in frozen plasma samples obtained from the participants prior to the thrombosis and acquired risk factors (trauma, surgery, immobility) prior to the time of the event.

\section{(5) Vascular factors in dementia}

In this project the role of blood pressure and other risk factors as determinants of vascular dementia will be investigated. The aim of this project is to develop a risk function which may be used for decisions concerning the treatment of mild to moderate hypertension in order to prevent vascular dementia. The risk function will be composed of variables measured in the Rotterdam Elderly Study and easily assessed in clinical practice, including blood pressure (isolated systolic hypertension), history of cerebrovascular disease (with emphasis on TIA's) and other cardiovascular diseases, major cardiovascular risk factors (serum lipids, smoking habits) and ECG characteristics. The risk function will be derived from a comparison of these variables among patients with vascular dementia and control subjects. This project should provide the basis for an intervention study on treatment of hypertension to prevent vascular dementia.

\section{(6) Socio-economic status and cardiovascular disease}

The objective of this project is to assess differences in cardiovascular morbidity and mortality between groups of different socio-economic status. The extent to which these differences can be explained by differences in cardiovascular risk factors and the modifying importance of social support is also examined. The study will be conducted in collaboration with the Rotterdam Municipal Health Authorities.

\subsubsection{Study design and methods}

\section{Design}

The Rotterdam Elderly Study is a longitudinal study of determinants of the occurrence of cardiovascular disease in an elderly population. A significant proportion of the research questions may be answered by means of the nested-case-control approach. The study is a prospective follow-up study of a cohort of 11,850 people, aged 55 years and over. In a period of five years the participants will be examined twice. During this period, and thereafter, the incidence of cardiovascular diseases and deaths will be assessed.

In the first part of the study the interplay between parameters of hemostasis and characteristics of blood vessels and the myocardium will be examined. In this phase, demonstrable atherosclerotic lesions as well as the vessel wall thickness and flow profiles of the carotid arteries will be registered. At the same time the wellknown "classic" risk indicators will be registered, so that the relative contribution of these diverse factors can be assessed. The latter include serum lipids, blood pressure, left ventricular mass, electrocardiographic abnormalities, glucose intolerance and insulin levels. In addition, the presence of aneurysmatic dilatation of the abdominal aorta, blood pressure changes across the peripheral arteries and the mental and cognitive performance of the participants will be measured. At the second examination about 2.5 years later all baseline parameters, including the blood vessel characteristics, will be re-examined. The role of hemostatic and other factors in the development and progression of atherosclerotic blood vessel and cardiac disease can then be assessed. During a follow-up period of at least five years the incidence of cardiovascular illness and death will be monitored. In this way it will be possible to study the risk for cardiovascular illnesses attributable to disturbances in hemostasis, blood vessel wall abnormalities and progression of atherosclerosis and to relate these factors to other risk factors.

The proposed study focusses on factors that explain the incidence of seriously handicapping forms of cardiovascular illnesses, such as angina pectoris, heart failure, stroke, intermittent claudication and "multiinfarct" dementia. Using the findings of the first and second phases of the study it will be possible to select groups which, on the basis of coagulation characteristics and/or blood vessel abnormalities, exhibit a higher than expected incidence of cardiovascular illness. These groups can then be used for yet to be determined additional studies on the effect of preventive measures.

\section{Methods}

The study forms a part of the Rotterdam Elderly Study and will be carried out among 4,570 men and 7,280 women aged 55 years and over, who reside in the district Ommoord of Rotterdam. During the study period every participant will be visited at home and examined at the research center. twice, the two examination rounds being 2.5 years apart. A venous blood sample will be taken for general biochemical determinations and the characterization of coagulation. Particular care will be taken to prepare plasma samples for storage at $-70^{\circ}$ Celcius, to allow future determinations of selected hemostatic parameters in case-control studies.

\subsubsection{Measurements}

The following data will be obtained at the home interview and clinical examination:

* Interview/questionnaires: medical history, drug history, family history, diet (semi-quantitative food 
frequency), cardiovascular illnesses (modified Rose questionnaire), Geriatric Mental State Examination, Mini Mental State Examination, physical activity, social and economic status, quality of life;

* Physical examination (limited);

* Anthropometry: height, body weight, hip to waist ratio (body fat distribution)

* Blood pressure (sitting and orthostatic response);

* ECG, resting (12 leads);

* Vascular and cardiac measurements: Ultrasonic Duplex scanning of carotid arteries, Doppler-blood pressure readings (dorsalis pedis artery, posterior tibial artery), 2-D echographic measurement of abdominal aortic dimensions, M-mode echocardiographic assessment of left ventricular wall mass and left ventricular dimensions;

* Glucose tolerance test;

* Venous blood sample.

\subsubsection{Hemostatic determinations: rationale and table of measurements}

The table of measurements lists the factors to be studied under five headings (Table 2). The selection of

TABLE 2. - The table indicates the hemostatic determinations to be performed in the Rotterdam Elderly Study.

\begin{tabular}{|c|c|c|c|c|c|}
\hline & Name & & & Name & \\
\hline \multirow[t]{5}{*}{ I. } & Platelets & & III. & Anticoagulants & \\
\hline & number & A & & AT-III & $\mathrm{A}$ \\
\hline & Beta-TG & A & & Prot. C Ag & $\mathrm{B}$ \\
\hline & Platelet F IV & B & & Prot. C Act & $\mathrm{A}$ \\
\hline & & & & Prot. S Agt & $\mathrm{B}$ \\
\hline \multirow[t]{14}{*}{ II. } & Coagulation & & & EPI & $\mathrm{B}$ \\
\hline & $\mathrm{APTT}$ & B & & Alpha-1-AT & $\mathrm{C}$ \\
\hline & fibrinogen & A & & $\mathrm{HC}-\Pi I$ & $\mathrm{C}$ \\
\hline & PT & $\mathrm{A}^{1}$ & & Thrombomodulin & $\mathrm{C}$ \\
\hline & F VII C & A & & & \\
\hline & F VII Ag & B & IV. & Fibrinolysis & \\
\hline & F VIII C & A & & Plasminogen & $\mathrm{B}$ \\
\hline & $\mathrm{F}$ VIII Ag & B & & $\mathrm{t}$-PA Act & $\mathrm{B}$ \\
\hline & F II Ag & B & & t-PA Ag & $\mathrm{B}$ \\
\hline & F X Ag & B & & PAI Act & $\mathrm{B}$ \\
\hline & VWF Ag & B & & Alpha-2-AP & $\mathrm{B}$ \\
\hline & FPA & B & & & \\
\hline & & & V. & Blood vessel wall & \\
\hline & & & & PGP & $\mathrm{C}$ \\
\hline \multicolumn{6}{|c|}{$\begin{array}{l}\mathrm{A}=\text { measured in total group; } \mathrm{A}^{1}=\text { in participants on oral } \\
\text { anticoagulant drugs only }\end{array}$} \\
\hline \multicolumn{6}{|c|}{$\begin{array}{l}B=\text { prepared and stored at }-70 \text { degr. celsius for future analyses } \\
\text { in selected cases and controls }\end{array}$} \\
\hline \multicolumn{6}{|c|}{$\begin{array}{l}\mathrm{C}=\text { prepared and stored at }-70 \text { degr. celsius; future analyses is } \\
\text { considered }\end{array}$} \\
\hline
\end{tabular}

factors was determined by the following considerations. The most important consideration for selection is the possibility that a new and important risk indicator will be found, preferably one that is amenable to prevention. A second aspect is the need to confirm conclusions of previously published studies. Finally, there are the special interests of the researchers involved in this project. On the basis of these considerations, it was decided that the major topics would be coagulation (II), especially factors that promote and inhibit coagulation, and blood vessel wall protein (V). In addition, the importance of fibrinolysis was recognized; therefore samples for measurement of fibrinolytic factors will be stored. However, the importance of these measurements needs further assessment.

In category I the platelet count will be determined for all participants. Platelet aggregation studies are labor intensive and require fresh blood specimens which presents great logistic problems (63). However, platelet activation may be an important determinant of subsequent cardiovascular events and progression of vessel wall abnormalities. Therefore, investigation of the secretion products of blood platelets has been chosen; at present only beta-thromboglobulin (BetaTG) is measured in all participants. Additional material will be prepared and frozen for further determinations, in particular within the framework of future casecontrol studies.

Category II includes a number of factors which previous studies have indicated to be involved in the development of cardiovascular disease. Amongst these are fibrinogen and factor VII $(52,64,65,104,105$, 107). A role for factor VIII has been suggested by the findings of Rosendaal et al. that surprisingly few patients with hemophilia $A$ die of a myocardial infarction (2). The Von Willebrand Factor (VWF) could be of importance because pigs lacking this protein are resistant to the development of atherosclerosis $(30,72)$. Factors II and $X$ have been included because they are essential indices for the estimation of proteins C and S. The APTT provides information both when shortened (high concentration of intrinsic clotting factors) and when prolonged (lupus anticoagulants). Prothrombin time (PT) is measured selectively in subjects on anticoagulant therapy. To gain an impression of thrombolytic activity in the circulation fibrinogen peptide A (FPA) is measured.

Interesting findings are expected for category III. These determinations will mainly be performed on the basis of case-control studies of a limited number of subjects, notably patients suffering from cardiovascular events during the follow-up period and controls. The importance of the complex system of interacting factors that counteracts the coagulation cascade during the initiation and progression of cardiovascular disease has not yet been the subject of investigation. Studies of patients with venous thrombosis have suggested that the protein $\mathrm{C}$ - protein $\mathrm{S}$ thrombolytic system is an important risk factor for cardiovascular disease, while a 
recent communication from Von Felten (personal communication) and experience in Leiden with 40 atherosclerotic patients point to the possible role of protein S. The extrinsic pathway inhibitor (EPI), alpha1 antitrypsin (alpha-1-AT) and heparin cofactor II (HCII) are recent additions to the regulating system of thrombin formation. It is thus recommended that these components be measured if this is possible.

Category IV comprises various parameters of fibrinolysis. Recently, in angina pectoris PAI was found to be positively correlated with triglycerides as well as with insulin $(36,50)$. In a prospective study PAI was associated with the incidence of reinfarction. Extensive ongoing prospective studies (NIH ARIC and ECAT AP) on cardiovascular diseases also include tPA and PAI assays $(100,101)$. Inclusion of some fibrinolysis assays in the study will be considered at a later date, the stored plasma samples can then be assessed.

Finally, the discovery of Plaque GLA-protein (PGP) offers the interesting possibility of a completely new direction for research on the development and prevention of atherosclerosis. In Maastricht, research activities focus on vitamin $\mathrm{K}$-dependent proteins which include not only the well-known coagulation proteins (II, VII, IX, X) and coagulation inhibitors (proteins C and S) but also osteocalcin and PGP that have been isolated from atherosclerotic plaques. Vitamin Kdependent proteins have the property of binding calcium and it is not unlikely that PGP has a part to play in the development of atherosclerosis. Because of these considerations, the opportunity to study this protein was included in this project.

\subsection{Locomotor diseases}

\subsubsection{Introduction}

Osteoarthritis and osteoporosis are the locomotor disorders that threaten in particular the mobility and independence of the elderly. Investigation of etiologic determinants is most promising for osteoporosis. In this section the study of osteoporosis and osteoarthritis is described.

\subsubsection{Osteoporosis}

\subsubsection{Scope of research}

The osteoporosis research project aims to identify determinants of the occurrence of hip and spinal fractures. A prospective follow-up study will be carried out in men and women, aged 55 years and over. X-ray films of the thoracolumbar spine and pelvis (hips) will be taken at entry, simultaneously with bone mineral density measurements at the sites of the lumbar vertebrae $\mathrm{L} I \rightarrow \mathrm{L}$ IV and, one-sided, the proximal femur. Baseline clinical data will be collected by interview and physical examination. Duration of follow-up will be 2.5 years. Then, baseline bone imaging procedures will be repeated. Fracture status will be recorded during follow-up. As a result of the study it should be possible to identify one or more groups with a high risk for age-related osteoporosis, in order to investigate fracture-risk reduction by specific interventions in randomized controlled trials. The osteoporosis project will also contribute regional data to a comparative study of geographical variations in osteoporosis prevalence between European populations.

\subsubsection{Research questions}

\section{Primary}

1. What is the incidence rate ratio and rate difference for vertebral and hip fractures in men and women with low versus high initial bone mineral parameters?

2. What are the determinants of vertebral and proximal femur fractures?

3. What are the determinants of bone mineral density in elderly men and women?

\section{Secondary}

1. Is it possible to construct a risk function for vertebral and proximal femur fractures, which can be used as a guide for intervention?

2. What is the association between bone mineral density and vertebral crush fractures and a history of limb fractures?

3. What are the determinants of the rate of bone mineral loss at spinal and proximal femur sites in elderly men and women?

4. Is the rate of bone mineral loss at one location (vertebrae) associated with that at another (proximal femur)?

5. What is the clinical significance of discrepancies in the outcome of the different bone mineral density assessments?

\subsubsection{Rationale}

One of the leading causes of fractures in the elderly is osteoporosis. Osteoporosis is defined as a decrease in bone mineral content leading to non-traumatic fractures. It is a serious health problem as far as the number and severity of cases is concerned and in terms of health care expenditures $(15,20,83)$. Women over 80 years of age exhibit a 15 to $20 \%$ higher mortality in the first year after hip fracture (20). The prevalence of vertebral fractures and hospital admissions for a proximal femur fracture increase markedly with age. Moreover, the age-adjusted incidence rates for hip 
fractures show an increase in some European countries, including the U.K. and the Netherlands $(8,44)$. Women of all ages run a higher risk for osteoporotic fractures than men.

The regulation of bone tissue mass and structure involves the coupled actions of osteoclastic and osteoblastic cells; the dynamic equilibrium between resorption and new bone formation is controlled by PTH and steroid hormones (80). Bone mass at a certain point in life is the net result of the peak bone mass reached in the third decade and the subsequent cumulative loss. Morphology of bone tissue depends on its anatomic localization. In the shafts of the long bones cortical bone predominates; in vertebrae, pelvis and other flat bones trabecular (or cancellous) bone is found, surrounded by a cortex. Different rates of bone mineral loss have been described for the cortical and trabecular types of bone in both men and women; therefore the processes of remodelling and breakdown of bone tissue are not uniform throughout the body ( 60 , $66,71)$. Moreover, the phase of accelerated loss in postmenopausal women is mainly one of cancellous bone loss $(45,60)$. These observations gave rise to the concept of dividing osteoporosis into type I: postmenopausal (affecting trabecular bone) and type II: age-related (predominantly loss of cortical bone) (82). Fractures at a site dominated by cortical or cancellous bone morphology can therefore be related to type I or type II osteoporosis. Recently, however, this classification system has been questioned because it appeared difficult to relate fracture occurrence patterns with the distribution of bone mineral mass and the unexpected low frequency of multiple common-type fractures in individual patients (19). In this respect, the prospective study of localization-specific fractures in relation to baseline bone mineral density at these spots will be most informative. The study of bone mineral dynamics at the lumbar spine and proximal femur in men and women will lead to new hypotheses on the contribution of osteoporosis to the etiology of fractures.

Osteoporosis is an important determinant of agerelated hip fractures, although not necessarily either the only or a sufficient one (67). Attention has been called to intrinsic bone factors such as fatigue and trabecular disconnection as an explanation for bone fragility, apart from simply the reduction in bone mass (38). Furthermore, extraneous factors such as cognitive function or drug use must be taken into account as a cause of falls and thus, for example, of hip fractures. In the Rotterdam Elderly Study the most important determinants of fall accidents are investigated in detail. Bone mineral density can thus be studied in relation to other determinants of fractures.

More than one bone mineral measurement technique applicable at either the axial or peripheral skeleton is in use today. There is no obvious best choice (93); even worse, correlations between measurements are disappointing $(5,84)$. The optimal bone mineral measurement technique for this population study needs to be a safe, quick, non-invasive method with high precision and reproducibility over time. Dual Energy $\mathrm{X}$-ray Absorptiometry (DEXA) promises to be the most appropriate technique. The standard software available allows us to assess bone mineral content and bone mineral density of lumbar spine and proximal femur in most cases with reasonable confidence. In this protocol, DEXA measurements of lumbar spine and a unilateral proximal femur will be carried out. Phalangeal radiodensitometry, i.e. bone mineral quantification based on estimates of the bone mineral density of crosssections of one phalangeal bone using the hand X-ray image, is an additional assessment (102).

Many questions remain about the prevention, early diagnosis and treatment of osteoporosis. Identification of risk factors for fractures and the construction of a fracture risk-function for selecting of high-risk groups within the elderly population is challenging, especially with a view to planning future clinical trials. This prospective study on the dynamics of bone mineral content at different skeletal sites will lead to new advances in our understanding of the etiologic role of well-established and putative determinants of bone mass. Moreover, the study will help to pave the way for the exploration of potential preventive strategies aimed at osteoporotic fractures at their clinically most important localisations: proximal femur and vertebrae.

\subsubsection{Study design}

\section{Population}

The osteoporosis research project is incorporated in the Rotterdam Elderly Study. This is a prospective follow-up study on the incidence and determinants of geriatric diseases in the general population. The initial baseline part of the study consists of an interview at the participant's home carried out by a (trained) research assistant, followed by a visit to the field center where the medical examinations will be performed.

\section{Cross-sectional study}

In the cross-sectional part of the study, the determinants of bone mineral density will be investigated. Radiographic evidence of vertebral fractures, as well as a history of limb fractures, will be studied in relation to their respective determinants.

\section{Study endpoints (follow-up study)}

\section{(1) Fracture of the hip.}

Information on cases will be obtained from the health care system. Details on fracture site will be described according to available X-ray examinations. The estimated annual number of fractures of the hip for our study population is $40-50$ for women and $10-15$ for men. 


\section{(2) Vertebral fractures.}

Data will be obtained by comparing individual baseline and follow-up X-ray examinations. Incident cases of new vertebral fractures in women over 70 years of age are estimated at $1 \%$ per year.

\section{(3) Bone mineral dynamics.}

Data on individual changes in bone mineral content will be obtained by comparing individual baseline and follow-up DEXA bone mineral density measurements of the lumbar vertebrea 2-4 and the proximal part of one femur.

\section{(4) Cause-specific death.}

Notification of death will be obtained from the municipal council and causes of death from the general practitioners.

\subsubsection{Measurements}

\section{(1) History}

* age, gender

* medical history: menarcheal age, menopausal age, oophorectomy, pharmacotherapy: current prescribed and non-prescribed drug use, previous use of estrogens, prednisone and antihypertensives, limb fractures in the past 5 years, diabetes mellitus, nephrolithiasis, rachitis, arthritis, cardiovascular disease, dementia, thyroid disease, smoking history

* dietary history: total calcium intake, phosphate,total calory intake, alcohol consumption

* physical activity

* sunlight exposure

* family history of hip fracture.

\section{(2) Physical examination}

* anthropometry: body height, sitting height, body weight, hip/waist ratio

* sphygmomanometry: sitting blood pressure, postural blood pressure change

* additional: electrocardiography, neurologic examination, visual acuity

\section{(3) Bone imaging}

* radiography: lateral films of the thoracic and lumbar spine (Th IV $\rightarrow$ L V); pelvis AP; hands and wrists

* bone mineral densitometry: DEXA of the lumbar spine (L II $\rightarrow$ L IV) and one proximal femur; phalangeal radiodensitometry.

To study changes over time, radiography and bone densitometry will be repeated three years after baseline.

\section{(4) Laboratory assessments}

* clinical chemistry and hormones in serum: ionized calcium, total calcium, sodium, potassium, glucose, creatinine, alkaline phosphatase, gamma glutaryl transferase, albumin, $25(\mathrm{OH})$ cholecalciferol, $1,25(\mathrm{OH})_{2}$ cholecalciferol (subgroup), estrogen (subgroup), testosterone (subgroup), sex-hormone binding globulin (subgroup), parathormone (subgroup), thyroid stimulating hormone, osteocalcin (subgroup)

* clinical chemistry in urine: sodium, calcium, (OH)proline (subgroup), creatinine

* hematology: erythrocyte sedimentation rate, hemoglobin.

\subsubsection{Specific projects}

\section{(1) Prevalence of vertebral fractures}

The study of the prevalence of vertebral osteoporotic fractures and their determinants will also be part of a collaborative project of the European Community. The possible causes of differences in regional prevalence figures will be investigated using a comparable methodology under the auspices of the European Vertebral Osteoporosis Study.

\section{(2) Intervention study of vitamin D}

Deficiency of vitamin $D$ is common in the elderly. Due to decreased calcium absorption and secondary hyperparathyroidism, this may lead to bone loss. In a randomized controlled trial the effect of vitamin D suppletion in septenarians will be studied. The incidence rate of hip fractures in the elderly over 70 years of age is high and still increasing. The primary endpoint for this subproject therefore is hip fracture.

\section{(3) Intervention study of calcitonin}

The recently available formulation for intranasal application makes calcitonin one of the most promising pharmacotherapeutics for primary and secondary prevention of osteoporotic fractures. The efficacy in bone mineral conservation and the relative safety of the drug potentially allow application on a broad scale. Once a high-risk group for the development of osteoporotic fractures can be defined within the population, this innovative calcitonin formulation deserves formal testing.

\subsubsection{Osteoarthritis}

The objective of this study is to investigate the determinants of disability in the elderly in relation to the high prevalence of radiographic osteoarthritis. Attention will be focussed on hip and knee abnormalities since they are the major causes of mobility handicaps. The concepts impairment, disability and handicap used here are those defined by the WHO (66). 


\subsubsection{Research questions}

1. What are the determinants of the occurrence or progression of disabilities?

2. What proportion of disabilities is associated with signs of radiographic osteoarthritis?

3. What are the determinants of disabilities, given that signs of radiographic osteoarthritis are present?

\subsubsection{Rationale}

Epidemiologic surveys in the past have demonstrated that signs of radiographic osteoarthritis are one of the most prevalent abnormalities among the elderly $(14,89)$. The discrepancies between radiographic signs, physical findings and symptoms are striking (13). Little is known about the prognosis of degenerative joint disease. It is clear that severe arthritic deformities are associated to a certain extent with disability and limitation of the activities of daily living.

In view of the ageing population it is worthwhile to investigate the quantity and severity of disabilities associated with degenerative joint diseases. Knowledge of the determinants of disability and progression of disability may lead the way to future intervention programs. Understanding the determinants of disability or progression in the presence of radiographic osteoarthritis may result in preventive strategies to modify the natural history of osteoarthritis.

\subsubsection{Measurements}

* Medical history, family history

* Present health status

* Physical examination, including knee and hip functions

* Assessment of selected activities of daily living by trained observers

* Radiography: X-ray films of hips, knees and hand/wrist

* Laboratory tests

\subsection{Ophthalmologic diseases}

\subsubsection{Introduction}

The four most common age-related causes of blindness in the Western world are age-related macular degeneration (AMD), cataract, diabetic retinopathy and glaucoma. After cataract extraction, vision is usually restored, but this is often not the case after treatment of the other three disorders. This is true especially for AMD, the major blinding disorder of old age. Therefore, it is essential to gain more insight into the etiology of AMD by studying its prevalence, incidence and determinants. According to blind registration data, AMD is the most common cause of blindness in the elderly in the United Kingdom $(1,31)$. In a populationbased study in the US (55), AMD came second to cataract while it ranked first in a similar U.K. study (32). There are considerable differences in the estimations of blindness derived from blindness registries and those based on population studies. Moreover, in the latter the number of non-responders varied from $21.9 \%$ (32) to $33 \%(55)$ and there is evidence that the percentage of blind people was much higher among these non-responders than among the responders $(24,32,55)$.

In The Netherlands such a population-based study has never been performed. The Age-Related Eye Analysis (AREA) Study will start as a prevalence study in connection with the Rotterdam Elderly Study. The data from the Rotterdam Elderly Study will be used to search for determinants with a possible etiologic significance for the previously mentioned eye disorders. The emphasis will be on AMD and glaucoma since these are the two main causes of visual impairment in the elderly. At a later stage a follow-up study is scheduled to assess the incidence of these disorders, investigate putative risk factors and perform intervention studies.

In AREA emphasis will be on AMD and glaucoma, since they are the main causes of visual impairment in the elderly in the Western world and also because their etiology is least known. The prevalences of glaucoma and AMD show a steep but non-parallel rise with advancing age from $1.4 \%$ and $4.0 \%$ to $2.9 \%$ and $15.4 \%$, respectively (55). For this reason as well as the need for sufficiently large subgroups to be able to study risk factors it was decided that all 11,850 potential participants should be examined.

\subsubsection{Scope of the AREA study}

The ultimate goal is to prevent the occurrence of severe invalidating eye disorders in the elderly. AREA focusses on the following points:

* Determination of prevalence (and in a later stage incidence) of major eye disorders causing visual impairment.

* Search for risk factors, especially for AMD and (low tension) glaucoma.

* Comparison with similar studies in the past and a simultaneous study in the London Inner City.

* Identification of subgroups for further intervention studies of glaucoma and AMD.

\subsubsection{Specific questions of AREA}

\section{Prevalence and incidence}

1.1 What is the prevalence and incidence of AMD in the elderly?

1.2 What is the prevalence and incidence of glaucoma in the elderly? 
1.3 What percentage of the aged population is visually handicapped or blind, according to the WHO criteria?

\section{Study of putative risk factors}

2.1 Are cardiovascular (atherosclerotic vessel disease, hypertension, abnormalities in lipid metabolism and hematological and coagulation disorders) and biochemical abnormalities or a positive family history associated with simple glaucoma, lowtension glaucoma or AMD?

2.2 Is cumulative lifetime light exposure or decreased iris or fundus pigmentation associated with AMD?

\subsubsection{Rationale}

Not much is known about the etiology of agerelated macular degeneration (AMD). As a rule AMD is preceded by the formation of drusen in the macula. Drusen are thought to be accumulations of degenerative cell material from the photoreceptors. Drusen may be inherited in an autosomal dominant way but are often sporadic. Exposure to light, the presence of blue eyes, abnormal serum zinc levels and abnormalities in skin elastin have also been mentioned as predisposing factors for AMD (24).

For the purpose of this study glaucoma may be divided into primary open angle (POAG) and closed angle glaucoma. POAG can be subdivided into two groups, one with high (POAGH) and the other with low (POAGL) eye pressure. Both the pathogenesis of POAGH and POAGL and the prevalence of POAGL are unknown (56). POAGH may be inherited as an autosomal dominant disorder. However, there are also many sporadic cases. Abnormalities in the constituents of the trabecular meshwork in the chamber angle of the eye have been pointed out as a possible cause of POAG but the etiology of these abnormalities is unknown. Lately cardiovascular disorders have been suggested as a main etiologic factor, especially for POAGL.

\subsubsection{Study design}

A total of 11,850 people, 55 years and over and residing in one city district of Rotterdam (Ommoord), will be invited to participate (see chapter 1 ). They will be visited in their homes by an investigator to answer questions that will be entered into a portable computer. At a later stage these people will be examined at the Rotterdam Elderly Study field center. The ophthalmic examination will be performed by ophthalmology residents under supervision of ophthalmologists. According to the schedule 20 patients will be seen daily; the first part of the study will take 2.5 years. If further diagnostic procedures or ophthalmological treatment is indicated, patients will be referred to the Institute of Ophthalmology of the Erasmus University.
Rotterdam. As a last step, data will be analyzed and cross-linked with other data from the Rotterdam Elderly Study. The study is scheduled to be repeated after 2.5 years in order to calculate incidence rates.

\subsubsection{Measurements}

* Refraction: autorefraction, lensometry, subjective refraction, best corrected visual acuity;

* Slit lamp biomicroscopy: routine slit lamp examination, depth of the anterior chamber angle;

* Keratometry;

* Applanation tonometry;

* Perimetry: semi-automatic testing;

* Funduscopy: direct and indirect ophthalmoscopy;

* Stereo and mono fundus color slides.

\section{APPENDIX}

The members of the four project groups and collaborating research groups are given in this Appendix.

\section{Neurogeriatric diseases}

A. Hofman, MD, Ph.D, principal investigator, Department of Epidemiology and Biostatistics, Erasmus University, Rotterdam; M.M.B. Breteler, MD, Department of Epidemiology and Biostatistics, Erasmus University, Rotterdam; J.J. Claus, MD, Department of Epidemiology and Biostatistics, Erasmus University, Rotterdam; T.J.M. van der Cammen, MD, Department of Internal Medicine I/Geriatrics, Erasmus University, Rotterdam; F. van Harskamp, MD, Department of Neurology, Dijkzigt, Erasmus University, Rotterdam; C.M. van Duyn, MSc, Department of Epidemiology and Biostatistics, Erasmus University, Rotterdam; W.J. Schudel, MD, Ph.D, Department of Psychiatry, Dijkzigt, Erasmus University, Rotterdam.

Collaborating groups include IVEG/TNO (Prof. D.L. Knook), Department of Biochemistry, University of Antwerp (Dr C. Van Broeckhoven), Department of Biochemistry, University of London (Dr J. Hardy), Psychiatric Centre, VU Amsterdam (Prof. W. van Tilburg), Department of Neurology, Academic Hospital, Utrecht (Prof. J. van Gijn), EURODEM Concerted Action on the Epidemiology of Dementia, Rotterdam, EURAGE, Concerted Action on Ageing and Diseases (Prof. D.L. Knook, Rijswijk, The Netherlands).

\section{Cardiovascular diseases}

D.E. Grobbee, MD, PhD, principal investigator, Department of Epidemiology, Erasmus University, 
Rotterdam; M.L. Bots, MD, Department of Epidemiology and Biostatistics, Erasmus University, Rotterdam; P.J. Breslau, MD, PhD, Department of Vascular Surgery, Rode Kruis Hospital, Den Haag; E. Briët, MD, PhD, Department of Hemostasis and Thrombosis Research, Academic Hospital, Leiden; F. Haverkate, PhD, project leader European Concerted Action on Thrombosis and Disabilities, Gaubius Institute-TNO, Leiden; P. Koudstaal, MD, PhD, Department of Neurology, Erasmus University, Rotterdam; J.P. Mackenbach, MD, PhD, Department of Public Health, Erasmus University, Rotterdam; H. Pleumeekers, MD, Departments of Family Practice and Epidemiology, Erasmus University, Rotterdam; H. Raat, MD, Municipal Health Service, Rotterdam; F.R. Rosendaal, MD, $\mathrm{PhD}$, Department of Hemostasis and Thrombosis Research and Dept. of Clinical Epidemiology, Academic Hospital, Leiden; R.P Stolk, MD, Department of Epidemiology and Biostatistics, Erasmus University, Rotterdam; J.C. van Swieten, MD, Department of Neurology, Academic Hospital, Utrecht; H.H.D.M. van Vliet, PhD, Department of Hematology, Academic Hospital, Rotterdam; J.C.M. Witteman, MSc, Department of Epidemiology and Biostatistics, Erasmus University, Rotterdam.

Collaborating scientists include J.H. van Bemmel, $\mathrm{PhD}$, Department of Medical Informatics, Erasmus University, Rotterdam; E. van der Does, MD, PhD, Department of General Practice, Erasmus University, Rotterdam; A.F. Casparie, School of Health Policy and Management, Erasmus University, Rotterdam; J. van Gijn, MD, PhD, Department of Neurology, Academic Hospital, Utrecht; G. Heiss, MD, Atherosclerosis Risk in the Community Study, University of North Carolina at Chapel Hill, USA; J.J.C. Jonker, MD, STAR Laboratory, Rotterdam; F.J. Kok, PhD, CIVO/TNO, Zeist; E.A. Loeliger, MD, PhD, Department of Hemostasis and Thrombosis research, Academic Hospital, Leiden; T.W. Meade, MD, MRC Epidemiology and Medical Care Unit, Northwick Park Hospital, Middlesex (UK); C. van der Meer, Department of Biochemistry, University of Limburg, Maastricht; R. Reneman, MD, PhD Department of Physiology, University of Limburg, Maastricht; J.T.R.C. Roelandt, MD, PhD, Department of Cardiology, Thorax center, Erasmus University, Rotterdam; J.C. van Swieten, MD, Department of Neurology, Academic Hospital, Utrecht; H. van Urk, $\mathrm{MD}, \mathrm{PhD}$, Department of Surgery, Erasmus University, Rotterdam; H.A. Valkenburg, MD, PhD, EMGO Institute, Free University, Amsterdam; R.F.A. Weber, MD, PhD, Department of Internal Medicine III, EUR; J. Wikstrand, $\mathrm{MD}, \mathrm{PhD}$, Wallenberg Laboratory for Cardiovascular Research, Gothenburg, Sweden.

\section{Locomotor diseases}

F.A. van den Ouweland, MD, PhD, principal investigator, Department of Epidemiology and
Biostatistics, Erasmus University, Rotterdam; J.C. Birkenhäger, $\mathrm{MD}, \mathrm{PhD}$, Department of Medicine III, Academic Hospital, Rotterdam; H.E. Schütte, MD, $\mathrm{PhD}$, Department of Radiology, Academic Hospital, Rotterdam; E. Odding, MD, Department of Epidemiology and Biostatistics, Erasmus University, Rotterdam; J.S.A.G. Schouten, MD, Department of Epidemiology and Biostatistics, Erasmus University, Rotterdam; H.A. Valkenburg, MD, PhD, EMGO Institute, Free University Amsterdam; P. Lips, MD, $\mathrm{PhD}$, Division of Endocrinology, Department of Medicine, Free University Amsterdam; A. Hofman, MD, PhD, Department of Epidemiology and Biostatistics, Erasmus University, Rotterdam.

This study participates in the European Vertebral Osteoporosis Study (A. Silman, ARC Epidemiology Research Clinic, Manchester, UK).

\section{Ophthalmologic diseases}

P.T.V.M. de Jong, MD, PhD, FCOphth principal investigator, Institute of Ophthalmology, Erasmus University, Rotterdam, and Dept. of Epidemiology and Biostatistics, Erasmus University, Rotterdam; I. Dielemans, MD, Institute of Ophthalmology, Erasmus University, Rotterdam; J.R. Vingerling, MD, Institute of Ophthalmology, Erasmus University, Rotterdam.

The study protocol was drafted in close collaboration with the Inner City Eye Study in London (Dept. of Preventive Ophthalmology, Cayton Street, Prof G.J. Johnson with the National Eye Institute (NIH Bethesda, USA), the Wilmer Eye Institute, Baltimore (USA) and the University of Erlangen (BRD) in order to ensure comparability with previous and current epidemiological studies.

\section{Acknowledgements}

The Rotterdam Elderly Study is made possible by financial support of Erasmus University Rotterdam; Erasmus University Medical School, Rotterdam; NESTOR, Stimulation programme for geriatric research in the Netherlands (Ministry of Health and Ministry of Education); Municipality of Rotterdam; Netherlands Hearth Fundation; Netherlands Organisation for scientific research (NWO); Netherlands Praeventionfunds; European Community; ROOS Foundation, Rotterdam; ROMERES Foundation, Rotterdam.

\section{REFERENCES}

1. Aclimandos W.A., Galloway N.R. Blindness in the City of Nottingham (1980-1985). Eye 1988; 2: 431-434. 
2. Allaart C.F., Aronson D.C., Ruys Th, et al. Hereditary Protein $S$ deficiency in young adults with arterial occlusive disease. Thromb Haemost 1991 (in press).

3. Amaducci L.A., Fratiglioni L., Rocca W.A., et al. Risk factors for clinically diagnosed Alzheimer's disease: a case-control study of an Italian population. Neurology 1986; 36: 922-31.

4. Aspirin Myocardial Infarction Study Research Group. A randomized controlled trial of aspirin in persons recovered from myocardial infarction. JAMA $1980 ; 243: 661-9$.

5. Berkum F.N.R. van, Birkenhäger J.C., van Veen L.C.P., et al. Noninvasive axial and peripheral assessment of bone mineral content: A comparison between osteoporotic women and normal subjects. J Bone Min Res 1989; 4: 679-85.

6. Bijl R.V., Nederlands Centrum voor de Geestelijke Volksgezondheidszorg, Scenariorapport. Onderzoek Geestelijke Gezondheidszorg. STG publication, in press.

7. Binswanger $O$. Die Begrenzung der allgemeinen progessiven Paralysie. Berl Klin Wochenschr 1894; 31: 1103-5, 1137-9, 1180-6.

8. Boyce W.J:Véssey M.P. Rising incidence of fracture of the proximal femur. Lancet 1985; 1 : $150-151$.

9. Breslau P.J. Ultrasonic Duplex scanning in the evaluation of carotid artery disease. Maastricht: Thesis, 1982.

10. Briët E., Engesser L., Brommer E.J.P., Broekmans A.W., Bertina R.M. Thrombophilia: its causes and a rough estimate of its prevalence. Thromb Haemost 1987; 58: 39-43

11. Canner P.L. Aspirin in coronary heart disease. Comparison of six clinical trials. Isr J Med Sci 1983; 19: 413-23.

12. Chandra V., Kohmen E., Schoenberg B.S. Head trauma with loss of conciousness as a risk factor for Alzheimer's disease using prospectively collected data. Neurology; 37: 152.

13. Claessens A.A.M.C., Schouten J.S.A.G., Vandenouweland F.A., Valkenburg H.A. Do clinical findings associate with radiographic osteoarthritis of the knee? Ann Rheum Dis 1991 (in press).

14. Cobb $S$. The frequency of rheumatic diseases. Harvard Un Press 1971, Cambridge.

15. Consensus Committee. Consensus development conference: prophylaxis and treatment of osteoporosis. Br Med J 1987; 295: 914-1915
16. Consensus Conference. Differential diagnosis of dementing diseases. JAMA 1987; 258: 3411-6.

17. Coon W.W. Epidemiology of venous thromboembolism. Ann Surgery 1977; 186: 194-9.

18. Copeland J.R.M., Kelleker M.J., Kellett J.M., et al. A semi-structured clinical interview for the assessment of diagnosis and mental state in the elderly: the Geriatric Mental State Schedule. Psychol Med 1976;6:439-49.

19. Cummings $J$. Are patients with hip fractures more osteoporotic? Am J Med 1985; 78: 487-494.

20. Cummings S.R., Kelsey J.L., Nevitt M.C., O'Dowd $K . J$. Epidemiology of osteoporosis and osteoporotic fractures. Epidemiol Rev 1985; 7 : 178-209.

21. Davies M.J., Thomas A. Thrombosis and acute coronary-artery lesions in sudden cardiac ischemic death. N Engl J Med 1984; 310: 1137-40.

22. Dewey M.E., Copeland J.R.M., Hofman A., eds. Case finding for dementia in epidemiological studies. Eurodem Report 1, Liverpool, 1990.

23. Duthie E.H., Glatt S.L.. Understanding and treating multi-infarct dementia. Clin Geriatr Med 1988; 9: 749-66.

24. Ferris F.L. Senile macular degeneration: review of epidemiologic features. Am J Epidemiol 1983; 118: 132-151.

25. Fitzgerald D.J., Roy L., Catella F., Fitz Gerald G.A. Platelet activation in unstable coronary disease. N Engl J Med 1986; 315: 983-9.

26. Fowkes F.G.R. The measurement of atherosclerotic peripheral arterial disease in epidemilogical surveys. Int J Epidemiol 1988; 17: 248-54.

27. Fried L.P., Bush T.L. Morbidity as a focus of preventive health care in the elderly. Epidemiol Rev 1988; 10: 48-64

28. Fries J.F. Ageing, natural death and the compression of morbidity. N Engl J Med 1980; 303: $130-5$.

29. Fries J.F., Green L.W., Levine S. Health Promotion and the compresion of morbidity. Lancet 1989; i: 481-3.

30. Fuster V., Walter Bowie E.J., Lewis J.C., Fass D.N., Owen C.A. Jr., Brown A.L. Resistance to arteriosclerosis in pigs with von Willebrand's disease. J Clin Invest 1978; 61: 722-730.

31. Ghafour I.M., Allan D., Foulds W.S. Common causes of blindness and visual handicap in the west of Scotland. Br J Ophthalmol 1983; 67: 209-213.

32. Gibson J.M., Lavery J.R., Rosenthal A.R. 
Blindness and partial sight in an elderly population. Br J Ophthalmol 1986; 70: 700-705.

33. Grobbee $D E$. Hart en vaatziekten. In: Van der Maas PJ, Hofman A, Dekker E, red. De epidemiologische basis van gezondheidsbeleid. Samson Stafleu: Alphen aan de Rijn, 1988.

34. Gunning-Schepers L.J., Barendregt J.J., Van der Maas P.J. Population interventions reassessed. Lancet 1989; i: 479-81.

35. Hachinsky V.C., Lasser N.A., Marshall J. Multiinfarct dementia: a cause of mental deterioration in the elderly. Lancet 1974; ii: 207-9-11.

36. Hamsten A., Walldius G., Szamosi A. et al. Plasminogen Activator Inhibitor in Plasma: Risk Factor for recurrent Myocardial Infarction. Lancet 1987; ii: $3-8$.

37. Haynes S.G., Feinleib M., eds. The epidemiology of ageing. NIH publication 80-969, 1980.

38. Heany R.P. Osteoporotic fracture space: a hypothesis. Bone Min 1989; 6: 1-13.

39. Henderson A.S. The epidemiology of Alzheimer's disease. Br Med Bull 1986; 42: 3-10.

40. Heptinstall $S$. Haematology, ethnography, and thrombosis. Br Med J 1987; 294: 3-4.

41. Heyman A., Wilkonson W.E., Stafford J.A., et al. Alzheimer's disease: a study of epidemiological aspects. Ann Neurol 1984; 15: 335-41.

42. Hofman A., Schutte W., Tanja T.A. et al. History of dementia and Parkinson's disease in 1st-degree relatives of patients with Alzheimer's disease. Neurology 1989, 39: 1589-92.

43. Hofman A., Rocca W.A., Brayne C., et al. The prevalence of dementia in Europe. Int J Epidemiol 1991 (in press).

44. Hoogendoorn D. Enkele gegevens over 64.453 fracturen van het proximale uiteinde van het femur (collum plus trochantergebied) 1967-1979. Ned Tijdschr Geneeskd 1982; 126: 963-968

45. Hui S.L., Wiske P.S., Norton J.A., Johnston C.C. A prospective study of change in bone mass with age in post menopausal women. J Chron Dis 1982;35:715-725

46. Huse D.M., Oster G., Killen A.R., Lacey M.J., Colditz G.A. The economic costs of non-insulindependent diabetes mellitus. JAMA 1989; 262 : 2708-13.

47. Inzitari D., Diaz F., Fox A. Vascular risk factors and leuco-araiosis. Arch Neurol 1985; 42: 951-9.

48. Iso M., Folsom A.R., Wu K.K., et al. Hemostatic variables in Japanese and Caucasian men. Am J Epidemiol 1989; 130: 925-34.
49. Jonker $C$., Hooijer $C$. Seniele dementie type Alzheimer. Dissertation VU Amsterdam, 1986.

50. Juhan-Vague I., Alessi M.C., Joly P. et al. Plasma Plasminogen Activator Inhibitor-1 in Angina Pectoris. Influence of Plasma Insulin and acutephase response. Arteriosclerosis 1989; 9: 362-66.

51. Kannel W.B., Wolf P.A., Castelli W.P., D'Agostino $R . B$. Fibrinogen and risk of cardiovascular disease: The Framingham study. JAMA 1987; 258: 11836.

52. Kannel W.B., Wolf P.A., McGee D.L., Dawber T.R., McNamara P., Castelli W.P. Systolic blood pressure, arterial rigidity and risk of stroke: The Framingham study. JAMA 1981; 245: 1225-9.

53. Krolewski A.S. Epidemiology of diabetes mellitus. In: Joslin's Diabetes Mellitus. Philadelphia: Lea \& Febiger, 1985.

54. Lechner H., Schmidt R., Bertha G., Justich E., Offenbacher H., Schneider G. Nuclear magnetic resonance image white matter lesions and risk factors for stroke in normal individuals. Stroke $1988 ; 19: 263-5$

55. Leibowitz H.M., Krueger D.E., Maunder L.R., et $a l$. The Framingham Eye Study Monograph. An ophthalmological and epidemiological study of cataract, glaucoma, diabetic retinopathy, macular degeneration, and visual acuity in a general population of 2631 adults, 1973-1975. Survey Ophthalmol 1980; 24: 335-610.

56. Leske M.C. The epidemiology of open-angle glaucoma: a review. Am J Epidemiol 1983;118:166-191.

57. Levy D., Garrison R.J., Savage D.D., Kannel W.B., Castelli W.P. Left ventricular mass and incidence of coronary heart disease in an elderly cohort. Ann Int Med 1989; 110: 101-7.

58. Levy D., Anderson K., Savage D.D., Kannel W.B., Christiansen J.C., Castelli W.P. Echocardiographically detected left ventricular hypertrophy: Prevalence and risk factors. Ann Int Med 1988; 108: 7-13.

59. Loeliger E.A. Oral anticoagulation in the secondary prevention of myocardial infarction. Acta Med Scand 1981; 210 (S651): 305-15.

60. Mazess R.B. On ageing bone loss. Clin Orthop Rel Res 1982; 165: 239-252.

61. McCormick $J$. and Skrabauch P. Coronary heart disease is not preventable by population interventions. Lancet 1988; ii: 839-41.

62. McKhann G., Drachman D., Folstein M., et al. Clinical diagnosis of Alzheimer's disease. Neurology $1984 ; 34$ : 939-44.

63. Meade T.W., North W.R.S. Population based 
distributions of haemostatic variables. $\mathrm{Br}$ Med Bull 1977; 33: 283-8.

64. Meade T.W., North W.R.S., Chakrabarti R, et al. Haemostatic function and cardiovascular death: Early results of a prospective study. Lancet 1980; i: $1050-4$

65. Meade T.W., Mellows S., Broznovic M., et al. Haemostatic function and ischaemic heart disease: Principal results of the Northwhick Park Heart Study. Lancet 1986; ii: 533-7.

66. Meier D.E., Orwoll E.S., Jones J.M. Marked disparity between trabecular and cortical bone loss with age in healthy men. Ann Int Med 1984; 101: 605-612.

67. Melton J.L., Wahner H.W., Richelson L.S., O'Fallon W.M., Riggs B.L. Osteoporosis and the risk of hip fracture. Am J Epidemiol 1986; 124: 254-261.

68. Merode van $T$. The use of a multi-gate pulsed Doppler system in the evaluation of the carotid artery circulation. Maastricht: Thesis, 1986.

69. Mortimer J., French L.R., Hutton J.T., et al. Head injury as a risk factor for Alzheimer's disease. Neurology 1985; 35: 264-7.

70. Nevitt M.P., Ballard D.J., Hallett J.W. Prognosis of abdominal aortic aneurysms: A population based study. N Engl J Med 1989; 321: 1009-14.

71. Newton-John H.F., Morgan D.B. The loss of bone with age, osteoporosis and fractures. Clin Orthop Rel Res 1970; 72: 229-252

72. Nichols T.C., Bellinger D.A., Johnson T.A., Lamb M.A., Griggs T.R. Von Willebrand's disease prevents occlusive thrombosis in stenosed and injured porcine coronary arteries. Circulation Res 1986; 59: 15-26.

73. Norris J.M., Dorman J.S., LaPorte R.E., et al. Clustering of premature mortality in 1,761 insulindependent diabetics and their family members.

74. Oliver M.F. Prevention of coronary heart disease. Propaganda, promises, problems and prospects. Circulation 1986; 73: 1-9.

75. Osborn G.R. The incubation period of coronary thrombosis. London: Butterworths, 1963.

76. Persantin-Aspirin Reinfarction Study Research Group. Part II. Secondary prevention with persantin and aspirin. J Am Coll Cardiol 1986; 7: 251-69.

77. Peto R., Gray R., Collins R., Wheatly K., Hennekens C., Jarnzorik K., Warlow C., Hafner B., Thompson E., Norton S., Gillilaud S., Doll R. Randomised trial of prophylactic daily aspirin in British male doctors. Br Med J 1988; 296: 313-6.
78. Pleumeekers H., van der Does E., Grobbee D.E. Screening for abdominal aortic aneurysms. (Re) Ned Tijdschr Geneeskd 1989; 133: 1522.

79. Prevention of cardiovascular disease among the elderly. Report of a WHO meeting. World Health Organization: Geneva, 1987.

80. Raisz L.G., Kream B.E. Regulation of bone formation. N Engl J Med 1983; 309: 29-35,83-89.

81. Reaven G.M. Role of insulin resistance in human disease. Banting lecture. Diabetes 1988; 37: 1595607.

82. Riggs B.L., Melton L.J. Evidence for two distinct syndromes of involutional osteoporosis. Am J Med 1983; 75: 899-901.

83. Riggs B.L., Melton L.J. Involutional osteoporosis. N Engl J Med 1986; 314: 1676-86

84. Riis B.J., Christiansen C. Measurement of spinal or peripheral bone mass to estimate early postmenopausal bone loss? Am J Med 1988; 84: 646-653.

85. Robertson D.A., Hale P.J., Nattrass $M$. Macrovascular disease and hyperinsulinaemia. Bull Clin Endocrin Metab 1988; 2: 407-24.

86. Rocca W.A., Amaducci L.A., Schoenberg B.S. Epidemiology of clinically diagnosed Alzheimer's disease. Ann Neurol 1986; 19: 415-24.

87. Rosendaal F.R. Life expectancy in hemophilia 1973-1986. Br J Haematol 1989; 71: 71-6.

88. Ross $R$. The pathogenesis of atherosclerosis - an update. N Engl J Med 1986; 314: 488-500.

89. Saasse J.L.C.M. van, Van Romunde L.K.J., Cats A., Vandenbroucke J.P., Valkenburg H.A. Epidemiology of osteoarthritis: Zoetermeer Survey. Ann Rheum Dis 1989; 48: 271-80.

90. Salonen R., Solonen J.T. Progression of carotid atherosclerosis and its determinants: A populationbased ultrasonography study. Atherosclerosis 1990; 81: 33-40.

91. Schoenberg B.S., Kokmen E., Ohazaki H. Alzheimer's disease and other dementing illnesses in a defined United States population: incidence rates and clinical features. Ann Neurol 1987; 22: 724-9.

92. Sixty Plus Reinfarction Study research group. A double-blind trial to assess longterm oral anticoagulant therapy in elderly patients after myocardial infarction. Lancet 1980: 989-993.

93. Slemenda C.W., Johnston C.C. Bone Mass measurement: which site to measure. Am J Med 1988; 84: 643-645.

94. Stahelin H.B. Senile dementia in relation to nutritional factors. Bibl Nutr Dieta 1986; 38: 13644. 
95. Stolk R.P., Grobbee D.E. Insulin and ischemic cardiovascular disease. J Drug Res 1990; 15: 1659.

96. Stout R.W., Crawford V. Active life expectancy and terminal dependency: Trends in long-term geriatric care over 33 years. Lancet 1988; i: 281-3.

97. Strasser T., ed. Cardiovascular care of the elderly. Geneva: World Health Organization, 1985.

98. Sulkava R., Erliunjuntti T., Palo J. Head injury in Alzheimer's disease and vascular dementia. Neurology 1985;35:1530-1.

99. The Steering Committee of the Physicians Health Study Research Group. Final report on the aspirin component of the ongoing Physicians' Health Study. N Engl J Med 1989; 321: 129-35.

100. The ARIC Investigators. The Atherosclerosis Risk in Communities (ARIC) Study: Design and Objectives. Am J Epidemiology 1989; 129: 687702.

101.Thompson S.G., Duckert F., Haverkate F. et al. The Measurement of Haemostasis factors in 16 European Laboratories: Quality Thrombosis and Haemostasis 1989; 61: 301-306.
102.Trouerbach W.Th., Hoornstra K., Birkenhäger J.C., Zwamborn A.W. Röntgendensitometric study of the phalanx. Diagn Im Clin Med 1985; 54: 6477.

103. Vroonhoven T. van. Screening for abdominal aortic anuerysms. Ned Tijdschr Geneeskd 1989; 133: 1061-2.

104. Watts $E$. Reduced fibrinolytic activity as cardiovascular disease risk-factor. Lancet 1986;ii:809.

105. Welin L., Svärsud K., Wilhelmsen L., Larsson B., Tibblin $G$. Analysis of risk- factors for stroke in a cohort of men born in 1913. N Engl J Med 1987; 317: $521-6$.

106. WHO. International Classification of Impairments, Disabilities and Handicaps. WHO, 1980, Geneva.

107. Wilhelmsen L., Svarsudd K., Korsan-Bengsten K., et al. Fibrinogen as a risk- factor for stroke and myocardial infarction. N Engl J Med 1984; 311 : 501-5.

108. Wilson D.B., Guyatt G.H, Streiner D.L. The diagnosis of dementia. CMAJ 1987; 137: 625-9. 